\title{
Effects of Additives on the Stacking Fault Annihilation in $\beta$-SiC Powder Compacts
}

\author{
Won-Seon SEO, Chul-Hoon PAI, Kunihito KOUMOTO and Hiroaki YANAGIDA \\ Department of Industrial Chemistry, Faculty of Engineering, The University of Tokyo, 7-3-1, Hongo, Bunkyo-ku, Tokyo \\ $\boldsymbol{\beta}$-SiC 中の積層欠陥の消滅に対する添加物の影響 \\ 徐 元善・裴 哲薰・河本邦仁・柳田博明 \\ 東京大学工学部工業化学科, 113 東京都文京区本郷 7-3-1
}

113

[Received June 7, 1991; Accepted September 19, 1991]

\begin{abstract}
Effects of the addition of $\mathrm{B}, \mathrm{Al}, \mathrm{Fe}$, and $\mathrm{C}$ on the annihilation of stacking faults (S.F.) in $\beta$-SiC powder compacts were investigated. The separability of the $\mathrm{X}$-ray diffraction lines, $K \alpha_{1}$ and $K \alpha_{2}$, was applied to the qualitative evaluation of the lattice strain to elucidate the annihilation phenomena. Dissolution of $\mathrm{B}$ or $\mathrm{Al}$ (rapid heating condition) into $\mathrm{SiC}$ grains enhanced the lattice strain suppressing both grain growth and S.F. annihilation. The second phases formed in $\mathrm{Al}$ (slow heating condition) and $\mathrm{Fe}$ addition to $\beta$-SiC promoted both grain growth and S.F. annihilation, while the residual free carbon in $\mathrm{C}$ - added $\beta$-SiC impeded the grain boundary movement and hence suppressed grain growth and S.F. annihilation.
\end{abstract}

Key-words : $\beta$-SiC, Stacking fault, Additives, Grain growth, Lattice strain, Second phase

\section{Introduction}

Silicon carbide is a highly useful material for both electronic and mechanical applications. When a powder compact of $\mathrm{SiC}$ is heat-treated at high temperatures in a normal sintering process, various changes such as grain growth, pore elimination, phase transformation, etc. occur. ${ }^{1)}$,2) Among those changes the annihilation process of stacking faults initially present within the grains is interesting and should be understood because they greatly affect the properties of a final product. ${ }^{3)-5 \text { ) }}$

We have already reported $^{4}$ that the stacking fault annihilation in a nominally pure (undoped) $\beta$-SiC powder compact occurs simultaneously with the grain growth which is supposedly controlled by surface diffusion and/or vapor transport. Incorporation of nitrogen into the $\mathrm{SiC}$ grains during firing in $\mathrm{N}_{2}$ atmosphere was found to enhance the lattice strain, which was considered to be the most important factor to suppress the mass transport rate.

For the pressureless sintering or even for the hotpressing various sintering aids (usually boron and carbon) are added to the starting $\mathrm{SiC}$ powder because of its low sinterability. ${ }^{6), 7)}$ Behavior and roles of these sintering aids have been controversial for many years but are not yet fully understood. There- fore, studying the effects of sintering aids on the annihilation of stacking faults is considered to be significant from this point of view.

In the present study, boron (B), aluminum ( $\mathrm{Al}$ ), carbon $(\mathrm{C})$, and iron ( $\mathrm{Fe}$ ) were chosen as additives. The former three elements are known to be the typical sintering aids, but the effect of $\mathrm{Fe}$ addition is unknown. Boron and aluminum are known to dissolve into the $\mathrm{SiC}$ lattice to make solid solutions, ${ }^{8)}$ while carbon and iron do not apparently form solid solutions. Hence, we thought that the effects of dissolution of additives and chemical reaction, ex. second phase formation, on the stacking fault annihilation could be examined separately through the systematic addition of these elements.

\section{Experimental procedure}

2.1 Heat treatment of $\boldsymbol{\beta}$-SiC powder compact

Beta-SiC powder (Central Glass Co., Ltd.) having $15.0 \%$ stacking fault density synthesized by carbothermal reduction of $\mathrm{SiO}_{2}$ was employed as a starting material. BET surface area, average particle size, and impurity contents of the powder are shown in Table 1. The powder was isostatically pressed in a rubber mold after prepressing in a unidirectional mold, and was annealed at $1775^{\circ}-2000^{\circ} \mathrm{C}$ for $0-1 \mathrm{~h}$ in an $\mathrm{Ar}$ or a $\mathrm{N}_{2}$ atmosphere.

\subsection{Analysis}

Gold was evaporated onto the fractured surface, and scanning electron micrographs (SEM) observations were conducted to examine the microstructure. The average grain size was calculated from the micrographs. X-ray diffraction (XRD) measurements of the crushed powders were conducted using $\mathrm{Cu} K \alpha$ radiation with a $\mathrm{Ni}$ filter and a graphite monochromator under the following conditions; scan-

Table 1. Properties of the $\beta$-SiC powder.

\begin{tabular}{|c|c|c|c|c|c|c|}
\hline \multirow{2}{*}{$\begin{array}{c}\text { BET } \\
\text { surface area } \\
\left(\mathrm{m}^{2} / \mathrm{g}\right)\end{array}$} & $\begin{array}{c}\text { average } \\
\text { particle size } \\
(\mu \mathrm{m})\end{array}$ & \multicolumn{4}{|c|}{ impurity (ppm) } \\
\cline { 3 - 7 } & 0.60 & $\mathrm{Fe}$ & $\mathrm{Al}$ & $\mathrm{Ca}$ & $\mathrm{Mg}$ & $\mathrm{Na}$ \\
\hline 17.4 & 144 & 212 & 90 & 12 & 12 \\
\hline
\end{tabular}


ning speed $=1 / 8^{\circ}($ in $2 \theta) \min ^{-1}$, time constant $=5 \mathrm{~s}$, receiving slit $=0.15 \mathrm{~mm}$. The intensities of the peaks at $33.6^{\circ}$ and $41.4^{\circ}(2 \theta)$ were measured and stacking fault density was calculated using the following equation:4)

$$
A=\frac{33.6^{\circ} \text { peak intensity }(2 \theta)}{41.4^{\circ} \text { peak intensity }(2 \theta)}
$$

Stacking Fault $=$

$$
\frac{A}{6.82 \times 10^{-2} A+2.27 \times 10^{-2}}+1.7 A^{3}(\%)
$$

The half-width of the (111) reflection peak $\left(35.6^{\circ}\right)$ was also measured and the Scherrer equation was used to calculate the crystallite size. Lattice parameter was calculated from the observed peak positions of (331), (420), and (422) reflections precisely determined by an internal method using high-purity silicon as a standard. The computer program which could separate $K \alpha_{1}$ from $K \alpha_{2}$ by Rachinger method was used to calculate the precise lattice parameters of $\beta$-SiC which showed only poor crystallinity.

\section{Results and discussion}

3.1 Simple method to evaluate the lattice strain Our previous study revealed that the dissolution of nitrogen into the $\mathrm{SiC}$ grains during firing in a $\mathrm{N}_{2}$ atmosphere induces the lattice strain and hence reduces the mass transport rate suppressing the annihilation of stacking faults. ${ }^{4)}$ This phenomenon was also confirmed for the powder employed in the present study as shown in Fig. 1, where the stacking fault density measured after annealing the powder compacts for $0.5 \mathrm{~h}$ is plotted as a function of annealing temperature. It is evident that the stacking fault density decreases with increasing annealing temperature and that the rate of stacking fault annihilation is suppressed in a $\mathrm{N}_{2}$ atmosphere.

The enhanced lattice strain introduced by the incorporation of nitrogen has already been verified by

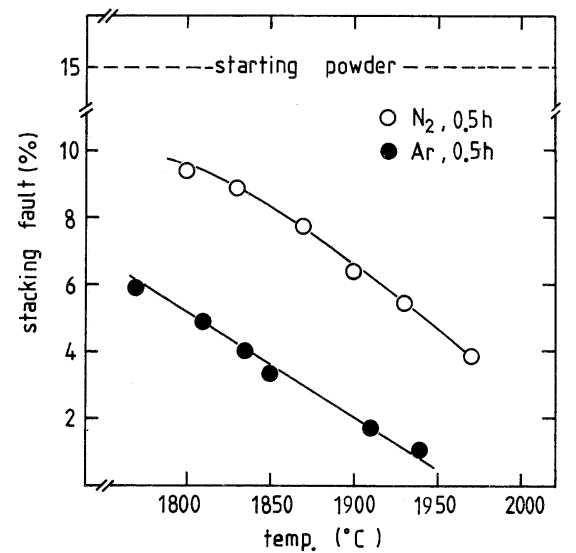

Fig. 1. Temperature dependence of the stacking fault density for the $\beta$-SiC compacts annealed for $0.5 \mathrm{~h}$ in $\mathrm{N}_{2}$ and $\mathrm{Ar}$ atmospheres. the direct measurement according to the Hall method. 4),9) However, this method is rather complicated and time consuming, so that it is not suitable to the evaluation of lattice strain for a large number of specimens. As an alternative simple method, the measurement of the separability of X-ray diffraction lines, $K \alpha_{1}$ and $K \alpha_{2}$, is proposed here.

In general, the width of an $\mathrm{X}$-ray diffraction line is associated fundamentally with the structural factors such as crystallite size, stacking fault density, and lattice strain. If the separability of the X-ray diffraction lines, $K \alpha_{1}$ and $K \alpha_{2}$, is defined to be either $A / B$ or $C /$ $D$ as shown in Fig. 2, it must have close relationships with those structural factors. In order to judge if the separability is applicable to evaluate the lattice strain, both undoped and nitrogen-doped $\beta$-SiC specimens were employed.

The $\beta$-SiC powder compact having $15 \%$ stacking fault density was annealed at various temperatures in either $\mathrm{N}_{2}$ or Ar atmosphere, and then crystallite size and stacking fault density were measured. The results are shown in Fig. 3. It is very interesting to note that the relation between the crystallite size and the stacking fault density is expressed by a "master" curve in a limited range irrespective of the annealing conditions.

We have further chosen the two specimens having approximately the same stacking fault density, $\sim 3.6 \%$, and the same crystallite size, $\sim 810 \AA$, and the separabilities were calculated for the various diffraction planes in terms of either $A / B$ or $C / D$. Figure 4 shows the calculated separability vs. the

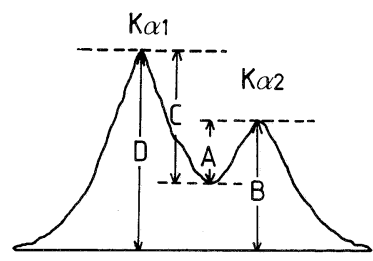

Fig. 2. X-ray diffraction profile in which the values for defining the separability are shown.

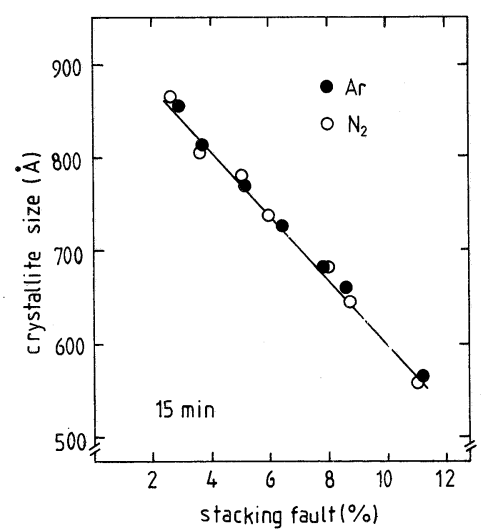

Fig. 3. Relation between the crystallite size and the stacking fault density for the specimens annealed at various temperatures for $15 \mathrm{~min}$ in $\mathrm{N}_{2}$ and $\mathrm{Ar}$ atmospheres. 


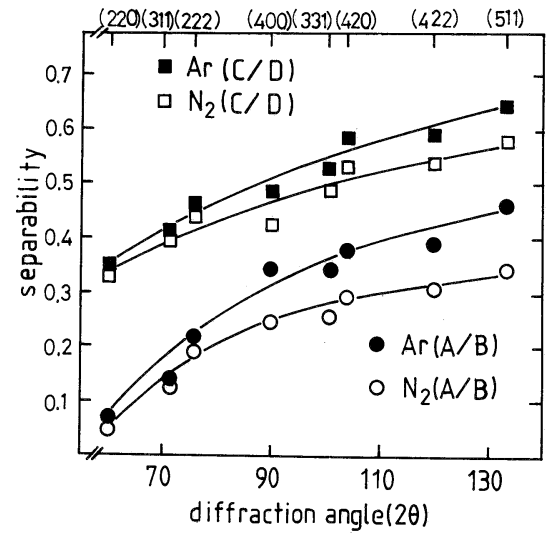

Fig. 4. Variations of the separability defined as either $A / B$ or $C /$ $D$ with the diffraction angle for the specimens which have similar crystallite sizes $(810 \AA)$ and stacking fault densities (3.6\%). Difference in the separability according to the firing atmospheres is clearly seen for all diffraction angles.

diffraction angle. It is clearly seen that the difference in $A / B$ or $C / D$ between the $\mathrm{Ar}$ - and $\mathrm{N}_{2}$-annealed specimens increased with increasing diffraction angle and $A / B$ gives larger differences than $C / D$. In either case, separability is always larger in an Ar-annealed specimen than in a $\mathrm{N}_{2}$-annealed specimen, which firmly indicates the nitrogen dissolution further introduces the lattice strain (the existence of lattice strain leads to a decrease in separability).

As a result, the separability of the X-ray diffraction lines, $K \alpha_{1}$ and $K \alpha_{2}$, can be easily measured and is judged to be applicable to evaluate, though qualitatively, the lattice strain introduced into $\beta$-SiC grains. Therefore, the separability was utilized in the present study to elucidate the effect of lattice strain on the stacking fault annihilation in $\beta$-SiC.

Before explaining the detailed experimental results, separabilities of the specimens with various kinds of additives measured using the (422) diffraction lines are presented here. Figure 5 shows the relationships between the separability and the stacking fault density for the specimens annealed at $1800^{\circ} \mathrm{C}$ for $0.5 \mathrm{~h}$ in $\mathrm{Ar}$. As has been expected, the separability decreases with increasing stacking fault density. The most significant feature to be noted in the figure is that the separabilities for the $\mathrm{Fe}$ - and $\mathrm{C}$ added specimens are generally larger than those for the B- and Al-added specimens, when compared at the same stacking fault density. This fact indicates that the dissolution of $\mathrm{B}$ or $\mathrm{Al}$ into $\mathrm{SiC}$ grains enhances the lattice strain, while undissolved $\mathrm{Fe}$ or $\mathrm{C}$ has little effect on the lattice strain, as will be verified from the lattice parameter variations described in the following sections.

\subsection{Effects of soluble additives on the stacking fault annihilation}

\subsubsection{Boron (B)}

Boron is known as an additive for solid state sintering and is commonly added with carbon. The effects of boron on the sintering behavior of $\beta$ - $\mathrm{SiC}$ have been

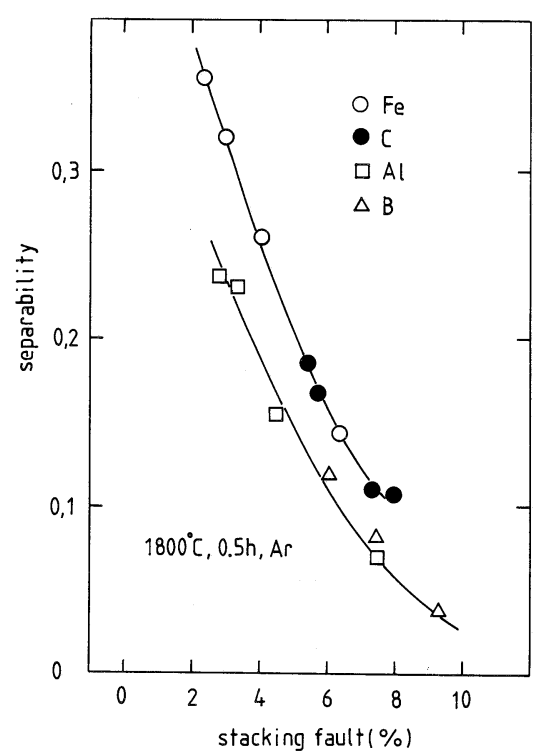

Fig. 5. Relation between the separability and the stacking fault density for the specimens with additives annealed at $1800^{\circ} \mathrm{C}$ for $0.5 \mathrm{~h}$ in $\mathrm{Ar}$.

widely studied by many researchers. Greskovich and Rosolowski10) showed that boron inhibits surface diffusion during heating up and so reduces particle coarsening. Murata and Smoak ${ }^{11)}$ reported that the formation of solid solution between $\mathrm{SiC}$ and boron compound ( $\mathrm{BN}, \mathrm{BP}, \mathrm{B}_{4} \mathrm{C}$ ) occurred during densification, and the maximum density of $\mathrm{SiC}$ body was obtained at the maximum solubility of additives. It is also expected that the addition of boron to $\beta$-SiC should have great effects on the annihilation of stacking faults.

Figure 6 shows the stacking fault density and lattice parameter for the $\beta$-SiC specimens with various boron contents after annealed at $1800^{\circ} \mathrm{C}$ for $0.5 \mathrm{~h}$ in Ar. It appears that the stacking fault density increases with increasing boron content, indicating that the annihilation of stacking faults becomes more suppressed as increasing $B$ content. Lattice parameter decreases with increasing boron content, exhibiting a high correlation with the change in the stacking fault density.

It is postulated from Fig. 6 that the substitutional solid solution may be formed when boron is incorporated into $\beta$-SiC lattice. Since the difference in covalent radii between $B(0.082 \mathrm{~nm})$ and $C(0.077 \mathrm{~nm})$ is smaller than that between $B$ and $\operatorname{Si}(0.111 \mathrm{~nm})$, it may be expected that $\mathrm{B}$ is incorporated into $\mathrm{C}$ site in $\mathrm{SiC}$. However, it is considered from decreasing lattice parameter that the added $\mathrm{B}$ dissolves into $\mathrm{Si}$ sites, or $\mathrm{C}$ and $\mathrm{Si}$ sites concurrently. It may be explained from the stability of chemical bonding. Both $\mathrm{B}-\mathrm{C}$ and $\mathrm{Si}-\mathrm{B}$ systems form binary compounds having the same structure, $\mathrm{B}_{4} \mathrm{C}$ and $\mathrm{SiB}_{4}$. The $\mathrm{B}-\mathrm{C}$ system is chemically and thermally much more stable than $\mathrm{Si}-\mathrm{B}$ system above $\sim 1400^{\circ} \mathrm{C} .{ }^{8), 12)}$

Figure 7 shows the average grain size as a func- 


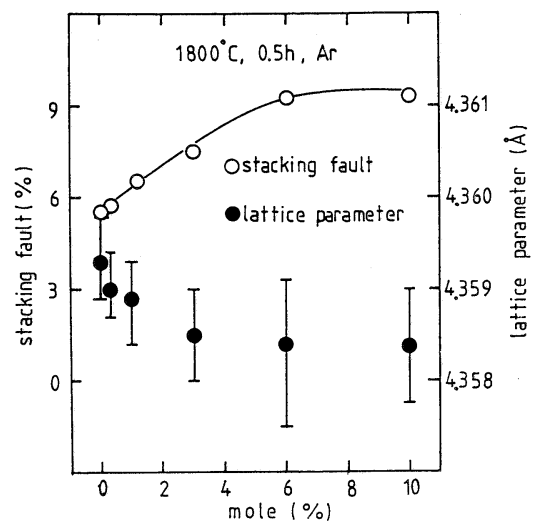

Fig. 6

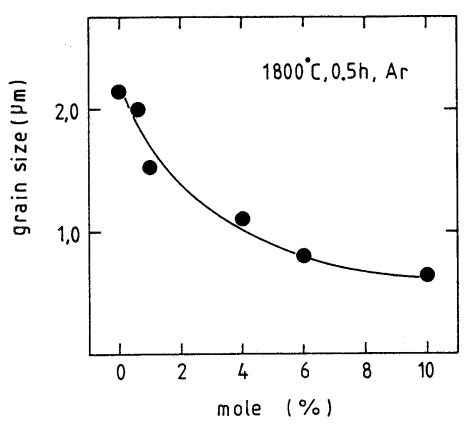

Fig. 7

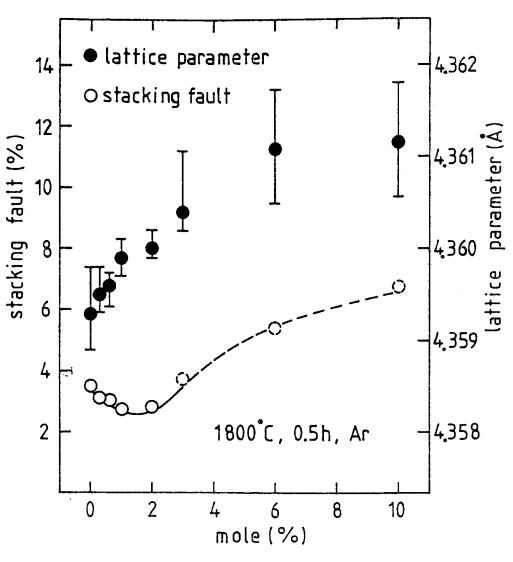

Fig. 8

Fig. 6. Stacking fault density and lattice parameter as functions of the amount of $\mathrm{B}$ addition for the specimens annealed at $1800^{\circ} \mathrm{C}$ for $0.5 \mathrm{~h}$ in Ar.

Fig. 7. Average grain size as a function of the amount of $\mathrm{B}$ addition for the specimens annealed at $1800^{\circ} \mathrm{C}$ for $0.5 \mathrm{~h}$ in $\mathrm{Ar}$.

Fig. 8. Variations in the stacking fault density and lattice parameter with the $\mathrm{Al}$ additive concentration for the specimens annealed at $1800^{\circ} \mathrm{C}$ for $0.5 \mathrm{~h}$ in $\mathrm{Ar}$. Specimens were slowly heated up to $1800^{\circ} \mathrm{C}$ at the rate of $4^{\circ} \mathrm{C} / \mathrm{min}$.

tion of B content. Grain size decreases with increasing $\mathrm{B}$ content. It should be noted that the change in grain size after annealing is closely related to the annihilation of stacking faults and the lattice parameter change. Dissolution of $\mathrm{B}$ into $\mathrm{SiC}$ grains enhances the lattice strain as mentioned in the previous section and hence decreases the rate of grain growth owing to the suppression of surface diffusion and/or vapor transport, just as the case for nitrogen-doped $\beta$-SiC.4) Stacking fault annihilation always takes place simultaneously with the grain growth, and hence the inhibition of grain growth causes the suppression of stacking fault annihilation.

\subsubsection{Aluminum (Al)}

Figures 8 and 9 show stacking fault densities and lattice parameters in the $\beta$-SiC specimens with various $\mathrm{Al}$ contents obtained after annealing at $1800^{\circ} \mathrm{C}$ for $0.5 \mathrm{~h}$ in Ar. The specimens in Fig. 9 were heated at the rate of $30^{\circ} \mathrm{C} / \mathrm{min}$ which is eight times as rapid as that for the specimens in Fig. $8\left(4^{\circ} \mathrm{C} / \mathrm{min}\right)$. In both cases, lattice parameter increased with increasing $\mathrm{Al}$ content. Regardless of the heating schedule, the solid solubility limit of $\mathrm{Al}$ is found to be about 6 mol\% (in an amount of addition) and the maximum value of lattice parameter is about $4.361 \AA$. However, the difference in the rate of annihilation of stacking faults is remarkable between the two heating schedules. In Figs. 8 and 9, symbols at 0 mol\% exhibit stacking fault density of undoped $\beta$-SiC after annealing. The difference in the stacking fault density at 0 mol\% may be due to the difference in the heating rate, since annihilation of stacking faults starts at about $1600^{\circ} \mathrm{C}$ in an $\mathrm{Ar}$ atmosphere.

It is widely accepted that thin Al-containing grain boundary films exist in $\mathrm{Al}$ - and $\mathrm{C}$-doped $\mathrm{SiC}, 13$ ) and that aluminum powder reacts with $\mathrm{SiC}$ to give $\mathrm{Al}_{4} \mathrm{C}_{3}$, $\mathrm{Al}_{4} \mathrm{SiC}_{4}$, and ternary (Al-C-Si) liquid phase at $700^{\circ}-1700^{\circ} \mathrm{C} .{ }^{14)}$ Figure 8 shows that annihilation of stacking faults is enhanced by the addition of a small amount (below $2 \mathrm{~mol} \%$ ) of $\mathrm{Al}$ under the slow heating condition. Therefore, in the case of slow heating, Al-containing second phase may be formed on the grain surfaces and grain boundaries at relatively low temperatures before the added $\mathrm{Al}$ dissolves into the grains. Then the mass transport rate is increased through the Al-containing second phase which becomes a liquid phase at higher temperatures. ${ }^{14)}$ The existence of Al-containing second phase must further have a large effect on the formation and growth of intergranular neck and the grain coarsening during annealing. Because annihilation of stacking faults occurs simultaneously with the grain growth, the existence of the second phase would enhance the stacking fault annihilation.

Under a rapid heating condition, annihilation of stacking faults is suppressed more than under a slow heating condition. It is assumed that the most of the added $\mathrm{Al}$ may directly dissolve into grains at high temperatures $\left(1800^{\circ} \mathrm{C}\right)$ without forming the second phase because of the rapid heating rate. It is considered from lattice parameter change that the lattice strain is introduced by solid solution formation owing to the different atomic radius of solute atoms. Under the high strain energy field, annihilation of stacking faults may be more difficult than under the low strain energy field.

In the case of adding more than $3 \mathrm{~mol} \%$ of $\mathrm{Al}$, $3 \mathrm{C} \rightarrow 4 \mathrm{H}$ phase transformation occurs as shown in Figs. 8 and 9. The precise calculation of stacking faults is impossible due to the superimposition of the (100) diffraction peak of the $4 \mathrm{H}$ phase on the $33.6^{\circ}$ peak $(2 \theta)$ of the $3 \mathrm{C}$ phase which is important for the calculation of stacking fault density. However, if the diffraction intensity of $(100)_{4 \mathrm{H}}$ is $25 \%$ of that of $(101)_{4 \mathrm{H}}$ according to the JCPDS card, the approximate calculation is possible. The results of the approximate calculation are shown by the broken lines in Figs. 8 and 9 for the specimens added with more 


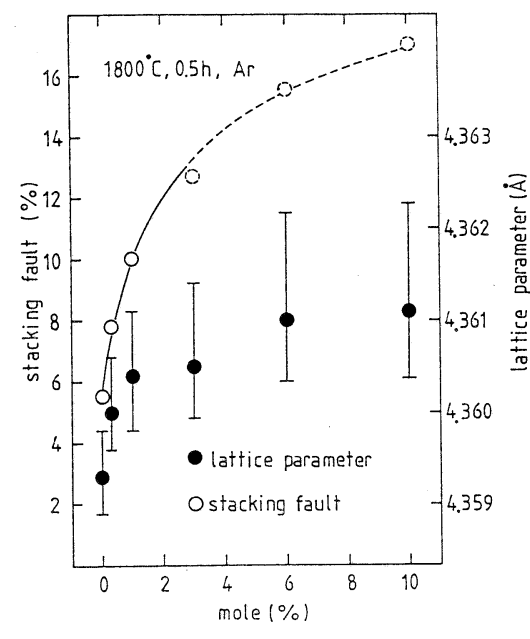

Fig. 9

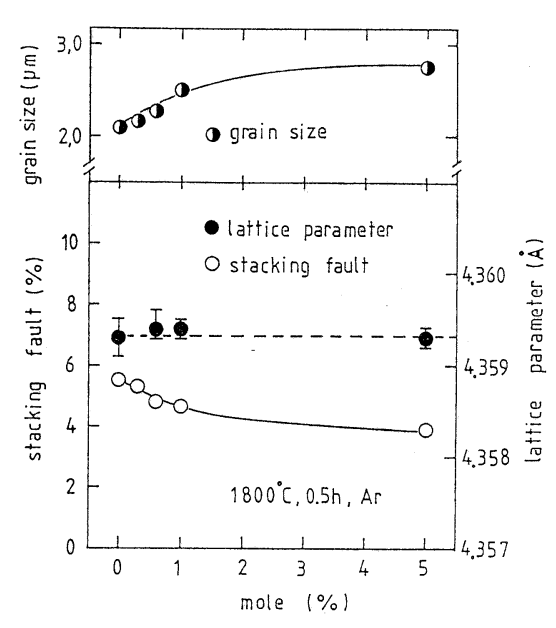

Fig. 10

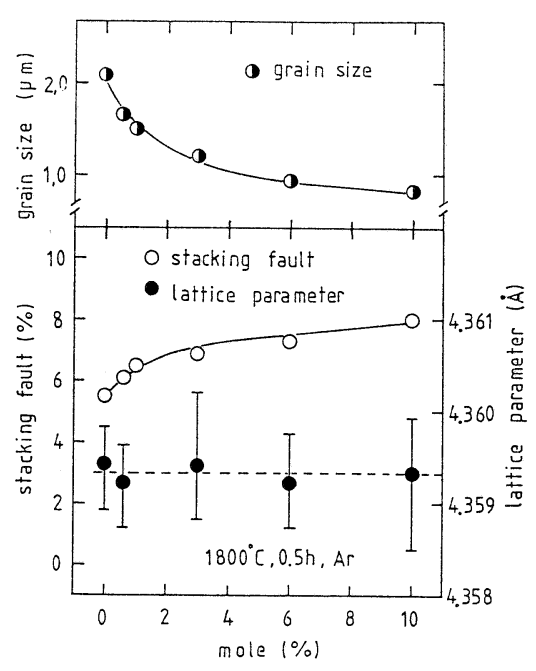

Fig. 11

Fig. 9. Variations in the stacking fault density and lattice parameter with the $\mathrm{Al}$ additive concentration for the specimens annealed at $1800^{\circ} \mathrm{C}$ for $0.5 \mathrm{~h}$ in $\mathrm{Ar}$. Specimens were rapidly heated up to $1800^{\circ} \mathrm{C}$ at the rate of $30^{\circ} \mathrm{C} / \mathrm{min}$.

Fig. 10. Variations in the stacking fault density, lattice parameter, and the average grain size with the Fe additive concentration for the specimens annealed at $1800^{\circ} \mathrm{C}$ for $0.5 \mathrm{~h}$ in $\mathrm{Ar}$.

Fig. 11. Variations in the stacking fault density, lattice parameter, and the average grain size with the $\mathrm{C}$ additive concentration for the specimens annealed at $1800^{\circ} \mathrm{C}$ for $0.5 \mathrm{~h}$ in $\mathrm{Ar}$.

than $3 \mathrm{~mol} \% \mathrm{Al}$. Though the phase transformation occurs, the stacking fault density increases with increasing content of added Al. Moreover, in the case of adding more than $6 \mathrm{~mol} \%$ for rapid heating, the stacking fault density appears to become larger than that of the starting powder (15\% stacking fault density). Also, $4 \mathrm{H}$ content increases with increasing content of the added Al. Consequently, it is considered that the degree of $3 \mathrm{C} \rightarrow 4 \mathrm{H}$ phase transformation is closely related to the annihilation and formation of stacking faults. However, the effects of stacking faults on the phase transformation are fairly complicated, and our investigation on this problem will be published separately.

\subsection{Effects of insoluble additives on the stack- ing fault annihilation}

\subsubsection{Iron ( $\mathrm{Fe})$}

Because good intrinsic properties of the sintered body of $\mathrm{SiC}$ cannot be expected under the existence of $\mathrm{Fe}$ and other metal impurities, the powder prepared by a conventional method is usually passed through the acid treatment to remove metal impurities. Hence, there have been few reports on the behavior of $\mathrm{Fe}$ in $\mathrm{SiC}$, in contrast with the number of reports on the sintering additives, such as $\mathrm{Al}, \mathrm{B}$ and C. Alliegro only reported that $3 \mathrm{~mol} \%$ addition of $\mathrm{Fe}$ was the most effective in promoting the densification of $\beta$-SiC by hot pressing. ${ }^{15)}$

However, by the present pressureless sintering, the relative density of the annealed body did not practically change with an increase in the amount of $\mathrm{Fe}$ addition, while the average grain size increased as shown in Fig. 10. Figure 10 also shows the changes in stacking fault density and lattice parameter for the Fe-added $\beta$-SiC specimens. It is evident that in- creasing amount of $\mathrm{Fe}$-addition promotes the annihilation of stacking faults and that the lattice parameter remains unchanged within experimental errors. Because there is no change in lattice parameter, lattice strain occurring from the dissolution of $\mathrm{Fe}$ atoms would never exist in the $\mathrm{Fe}$-added $\beta$ $\mathrm{SiC}$. Therefore, the promotion of stacking fault annihilation must have been caused by other microstructural factors.

An increase in the grain size as increasing Fe content is due to the enhancement of surface diffusion and/or vapor transport rate which controls the initial stage of sintering in $\beta$-SiC at relatively low temperatures. The added Fe powders could form a liquid phase, since $\alpha$-FeSi whose melting point is $1410^{\circ} \mathrm{C}^{16}$ ) is always detected by XRD when more than $1 \mathrm{~mol} \%$ of $\mathrm{Fe}$ is added. Then, Fe-based melt covers the grain surfaces and possibly grain boundaries, which would promote the grain growth through the liquid phase transport and hence disappearance of small grains leads to the enhancement of stacking fault annihilation according to the previously proposed mechanism.4)

\subsubsection{Carbon (C)}

The addition of carbon to $\beta$-SiC as a sintering additive has been reported by many researchers.6),17)-19) The added carbon probably removes the oxygen from the surface of $\mathrm{SiC}$ particles through the following reaction: ${ }^{17), 18)}$

$$
\mathrm{SiO}_{2}+3 \mathrm{C} \rightarrow \mathrm{SiC}+2 \mathrm{CO}
$$

The removal of surface oxide causes an increase in the surface area and thus in the surface energy of a particle. ${ }^{6)}$ An increase in the surface energy is expected to promote the grain growth. However, the grain size of $\beta$-SiC decreased with increasing content 
of carbon as shown in Fig. 11. Although the surface oxide turns into the newly formed $\mathrm{SiC}$ and exhausted $\mathrm{CO}$ gas according to the reaction (1), the residual unreacted carbon would impede the grain growth by pinning the grain boundary movement. ${ }^{19)}$

Figure 11 shows the changes in stacking fault density and lattice parameter for the $\mathrm{C}$-added $\beta$-SiC specimens. Stacking fault density increases but lattice parameter remains unchanged with increasing $\mathrm{C}$ content. As the amount of the added $\mathrm{C}$ is increased, the annihilation of stacking faults becomes suppressed. Since lattice strain introduced by the dissolution of $\mathrm{C}$ in $\beta$-SiC grains does not exist, the suppression of stacking fault annihilation must be attributed to the inhibition of grain growth.

Acknowledgment The authors express their sincere thanks to Mr. T. Ono and Mr. R. Tanaka of Central Glass Co., Ltd. for supplying the specially ordered $\beta$-SiC powders.

\section{References}

1) W. F. Knippenberg, Phillips Res. Rep., 18, 161-274 (1963).

2) S. Prochazka, "Ceramics for High Performance Applications", J. Burk, A. E. Gorun and R. M. Katz Ed., Brook Hill, Chestnut Hill, MA (1974) pp. 239-52.

3) K. Koumoto, S. Takeda, C. H. Pai, T. Sato and H. Yanagida, J. Am. Ceram. Soc., 72, 1985-87 (1989).

4) W. S. Seo, C. H. Pai, K. Koumoto and H. Yanagida, Seramik- kusu Ronbunshi (J. Ceram. Soc. Japan), 99, 443-47 (1991). 5) K. Koumoto, C. H. Pai, S. Takeda and H. Yanagida, Proc. 8th Int. Conf. on Thermoelectric Energy Conservation and 2nd Europe Conf. Thermoelec., Ed. by H. and S. Scherrer, Nancy, France (1989) pp. 107-12.

6) S. Prochazka, Special Ceramics 6, British Ceramic Research Association (1975) pp. 171-82.

7) F. F. Lange, J. Mater. Sci., 10, 314-20 (1975).

8) Y. Tajima and W. D. Kingery, J. Am. Ceram. Soc., 65, C2729 (1982).

9) W. H. Hall, Proc. Phys. Soc., A62, 741-43 (1949).

10) C. Greskovich and J. H. Rosolowski, J. Am. Ceram. Soc., 59, 336-43 (1976).

11) Y. Murata and R. H. Smoak, Proc. Int. Symp. of Factors in Densification and Sintering of Oxides and Non-Oxide Ceramics, Ed. by S. Sōmiya and S. Saito, Hakone, Japan (1978) pp. 382-99.

12) R. D. Allen, J. Am. Chem. Soc., 75, 3582-83 (1953).

13) R. Hamminger, G. Grathwohl and F. Thummler, J. Mater. Sci., 18, 3154-60 (1983).

14) J. C. Viala, P. Fortier and J. Bouix, ibid., 25, 1842-50 (1990).

15) R. A. Alliegro, L. B. Coffin and J. R. Tinklepaugh, J. Am. Ceram. Soc., 39, 386-89 (1956).

16) R. Schmid, CALPHAD, 4, 101-08 (1980).

17) H. Tanaka, Y. Inomata, K. Hara and H. Hasegawa, J. Mater. Sci. Lett., 4, 315-17 (1985).

18) P. Elder and V. D. Krstic, J. Mater. Sci. Lett., 8, 941-43 (1989).

19) E. R. Maddrell, J. Mater. Sci. Lett., 6, 486-88 (1987). 